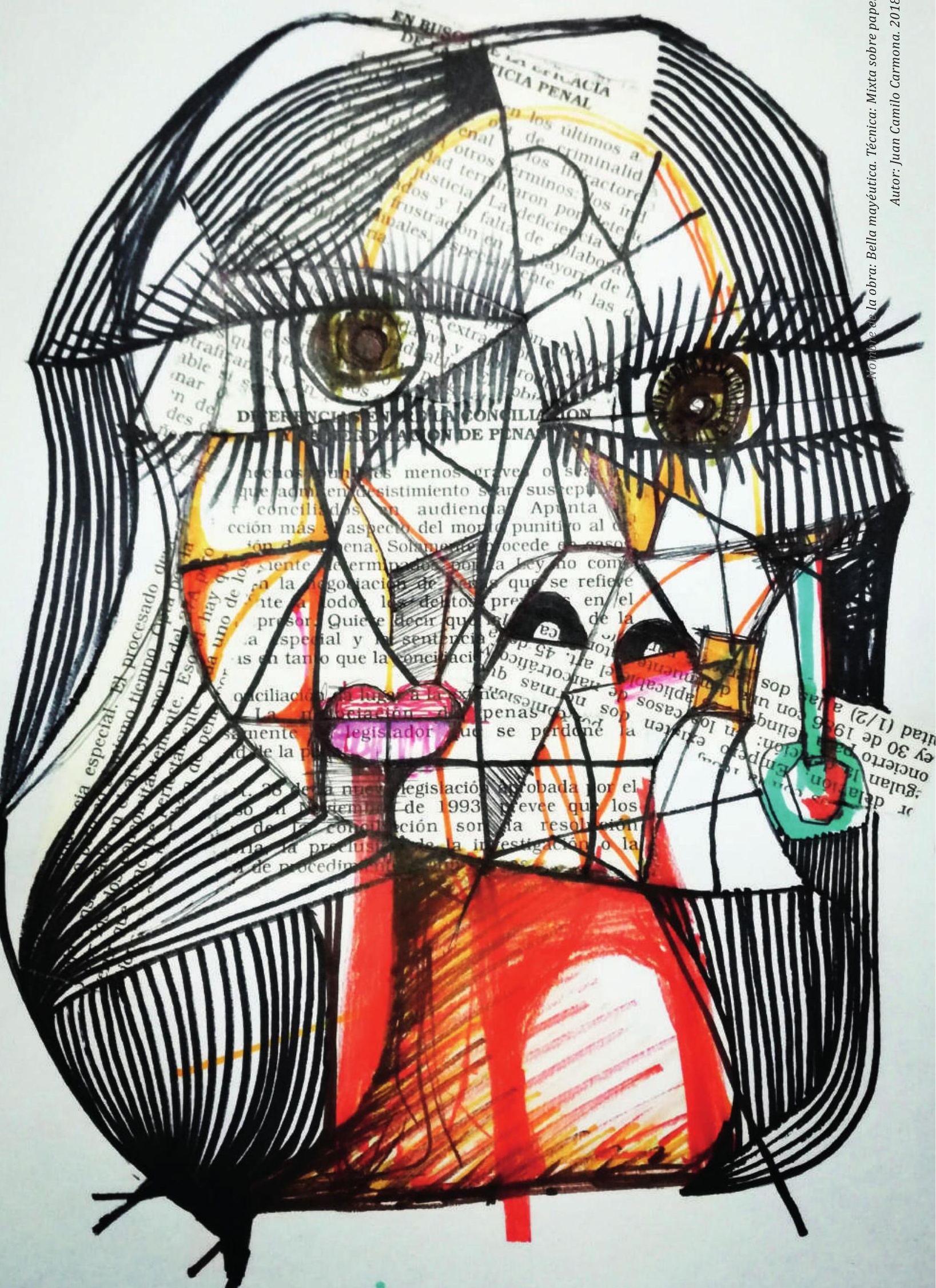




\section{La solución política del conflicto armado y la reivindicación de la memoria como política cultural de las víctimas de crímenes de Estado: el caso de la Fundación Manuel Cepeda Vargas*}

\section{Andrés Tafur Villarreal $* *$}

\section{Resumen}

A través del estudio del caso de la "Fundación Manuel Cepeda Vargas para la Paz, la Justicia Socialy la Cultura", este artículo se interroga por la política cultural de las víctimas de crímenes de Estado en la construcción de paz en Colombia y propone una explicación ligada directamente a la agencia de la Fundación, acerca de los mecanismos que hicieron posible que los reclamos de las víctimas se instalaran en la agenda pública. El primero tiene que ver con la introducción de nuevos repertorios que hicieron más efectiva la denuncia de los crímenes de Estado y la pedagogía social de la memoria históricay, el segundo, con la dirección política que le imprimióa la reivindicación de los derechos humanos, para articularla con la solución política del conflicto armado. Se argumenta que la consolidación de estos dos mecanismos hizo posible el posicionamiento de las víctimas de crímenes de Estado en el debate público, y su reconocimiento en el Acuerdo de Víctimas de La Habana.

Palabras clave: política cultural; construcción de paz; víctimas; crímenes de Estado; memoria.

\section{The Political Solution to the Armed Conflict and the Memory Claim as Cultural Politics for Victims of State Crimes: the case of the "Fundación Manuel Cepeda Vargas"}

\section{Abstract}

Through the case study of the "Fundación Manuel Cepeda Vargas para la Paz, la Justicia Social y la Cultura", this article interrogates the cultural politics of the Victims of State Crimes in the peacebuilding process in Colombia and proposes an explanation, directly linked to the Foundation's agency, about the mechanisms that made it possible for victims' claims to be placed on the public agenda. First, the new repertories introduction that made the complaint of State crimes and the social pedagogy of historical memory more effective. Second, the political leadership in the vindication of the Human Rights, to articulate it with the political solution to the armed conflict. The article argues that the consolidation of these two mechanisms made it possible the positioning of the victims of State crimes in the public debate, and its recognition in the "Acuerdo de Victimas de La Habana".

Keywords: cultural politics; peacebuilding, victims; State crimes; memory.

\section{A solução política do conflito armado e a reivindicação da memória como política cultural das vítimas de crimes de Estado: o caso da Fundação Manuel Cepeda Vargas}

\section{Resumo}

Através do estudo do caso da "Fundação Manuel Cepeda Vargas para a Paz, a Justiça Social e a Cultura", este artigo questiona-se sobre a política cultural das vítimas de crimes de Estado na construção de paz na Colômbia e propõe uma explicação ligada diretamente com a agência da Fundação, sobre os mecanismos que tornaram possível que as reivindicações das vítimas se instalassem na agenda pública. 0 primeiro tem a ver com a introdução de novos repertórios que tornaram mais efetiva a denúncia dos crimes de Estado e a pedagogia social da memória histórica e, o segundo, com a direção política que conferiu à reivindicação dos direitos humanos, para articulá-la com a solução política do conflito armado. Argumenta-se que a consolidação destes dois mecanismos tornou possível o posicionamento das vítimas de crimes de Estado no debate público, e o seu reconhecimento no Acordo de Vítimas de Havana.

Palavras-chave: política cultural; construção de paz; vítimas; crimes de Estado; memória.

\footnotetext{
* Artículo de reflexión. Se desprende del proyecto: Política cultural y construcción de paz en Colombia: el caso de la Fundación Manuel Cepeda Vargas para la Paz, la Justicia Social y la Cultura", financia do por la Universidad del Tolima en el marco del proyecto "Talento Humano: Formación de Talento Humano de Alto Nivel en el Tolima. Fase 2: Maestrías, Doctorados y Postdoctorados en el país yen el exterior". Avalado por el Colectivo de Investigación en Arte y Cultura.

**Filósofoy Comunicador Social. Magister en Ciencia Política. Estudios de maestría enconstruccióndepazen la Univer-sidad de los Andes. Docente de la Universidad del Tolima, Colombia. Colectivo de Investigación en Arte y Cultura. Coordinador del semillero Paz, violencia y orden social. Correo electrónico: jatafurv@ut.edu.co ORCID: 0000-0002-2497-4016
}

Cómo citar este artículo:Tafur, A. (2019). Lasolución política del conflictoarmadoyla reivindicación dela memoria como bolítica cultural de las víctimas de crímenes de Estado: el caso de la Fundación Manuel Ceneda Vargas. Estudios de Derecho, 76 (167), pp-pp. 113-142 


\section{La solución política del conflicto armado y la reivindicación de la memoria como política cultural de las víctimas de crímenes de Estado: el caso de la Fundación Manuel Cepeda Vargas}

\section{Introducción}

El Acuerdo de paz firmado por la guerrilla de las FARC-EP (Fuerzas Armadas Revolucionarias de Colombia, Ejército del Pueblo) y el Estado colombiano ${ }^{1}$, podría considerarse el punto de llegada de diversos esfuerzos oficiales y no oficiales por la consolidación de una paz estable y duradera, por lo menos en dos sentidos: en uno amplio, porque amalgama una serie de aprendizajes institucionales, producto de los emprendimientos que distintos gobiernos nacionales realizaron con el objetivo de negociar políticamente la terminación de la guerra con distintos grupos armados durante los últimos 30 años (Chernick, 2012; Bouvier, 2014; López, 2016); y en uno específico, porque oficializa buena parte de las agendas que durante décadas movilizaron las Organizaciones no Gubernamentales (ONG) defensoras de derechos humanos y las organizaciones de víctimas, en sus luchas por el reconocimiento de sus derechos a la verdad, la memoria, la justicia y la reparación.

Colombia ha tenido un movimiento de víctimas activo, que se consolidó de manera exitosa como un actor político de primer nivel en el escenario nacional (Aranguren, 2012; Mosquera, 2015; Rettberg, 2015a; Acebedo, 2016). La centralidad reconocida oficialmente en el Sistema Integral de Verdad, Justicia, Reparación y No Repetición - SIVJRNR, pactado en el Acuerdo de Víctimas de La Habana² ${ }^{2}$ y los

1 La fase pública de los diálogos entre la guerrilla de las Farc-Ep, y el gobierno de Juan Manuel Santos, se realizó en La Habana, Cuba, entre octubre de 2012 y agosto de 2016. El "Acuerdo Final para la Terminación del Conflicto y la Construcción de una Paz Estable y Duradera”, es resultado de la negociación de una agenda de seis puntos, compuesta por 1. Reforma Rural Integral, 2. Participación Política, 3. Terminación del Conflicto Armado, 4. Solución al Problema de las Drogas Ilícitas, 5. Víctimas, 6. Refrendación, implementación y verificación. El SIVJRNR está conformado por la "Comisión para el esclarecimiento de la verdad, la convivencia y la no repetición”, la “Unidad especial para la búsqueda de personas dadas por desaparecidas en el contexto y en razón del conflicto armado", la "Jurisdicción especial para la paz, las Medidas de reparación integral para la construcción de la paz" y las "Garantías de no repetición".

2 El SIVJRNR está conformado por la "Comisión para el esclarecimiento de la verdad, la convivencia y la no repetición”, la "Unidad especial para la búsqueda de personas dadas por desaparecidas en el contexto y en razón del conflicto armado", la "Jurisdicción especial para la paz, las Medidas de reparación integral para la construcción de la paz" y las “Garantías de no repetición". Las dos características del Acuerdo de Víctimas son precisamente, por un lado, su 
reconocimientos limitados a través de los marcos transicionales que lo precedieron en materia de verdad, justicia y reparación ${ }^{3}$, son resultado de la convergencia de distintos factores que operaron en varios niveles, siendo las víctimas uno de los actores más relevantes ${ }^{4}$ (Gómez, 2015).

Dentro de la clasificación de las iniciativas no oficiales de memoria en Colombia ${ }^{5}$, realizada por el Grupo de Memoria Histórica (2009), este artículo se concentra en las "Memorias contra la impunidad", cuya movilización reclama "la búsqueda de la verdad y la justicia en torno a los crímenes cometidos por agentes del Estado y luchan por la reparación integral de las víctimas" (GMH 2009, p. 174). De acuerdo con Acebedo (2016), la categoría "víctimas de crímenes de Estado" o "víctima de la criminalidad estatal" es usada por parte de "organizaciones de izquierda y del movimiento de derechos humanos colombiano para autonombrarse y nombrar a un grupo social que ha sido vulnerado por la acción del Estado en razón de sus creencias políticas" (Acebedo, 2016, p. 210, 211). Con ello han logrado crear y posicionar una identidad colectiva que han llenado de contenido y les ha posibilitado la acción. En este artículo se usará esa categoría en ese sentido.

Dado que el Acuerdo de Víctimas parte del reconocimiento de la responsabilidad de agentes estatales en violaciones a los DDHH y al DIH con ocasión del conflicto armado, tomando distancia del antecedente "negacionista" de las leyes de Justicia y Paz y de Víctimas y Restitución de Tierras ${ }^{6}$, queda un interrogante

vocación de sistema, que apunta a que los distintos mecanismos que vehiculan los principios de la justicia transicional (JT) sean implementados de manera coordinada e interconectada, sin que implique un solapamiento de funciones ni algún tipo de superioridad de unos mecanismos sobre otros. Y por el otro lado, la centralidad que ocupan las víctimas, o, lo que es lo mismo, el imperativo de resarcirlas y reconocerlas como "sujetos de derechos".

3 Se trata de las leyes 975 de 2005, o Ley de Justicia y Paz, y 1448 de 2011o Ley de Víctimas y Restitución de Tierras. La primera introdujo mecanismos transicionales que por primera vez reconocieron los derechos de las víctimas de los grupos armados ilegales en materia de verdad, justicia, reparación y garantías de no repetición. La segunda institucionalizó los derechos de las víctimas, haciendo énfasis en el derecho a la reparación integral (restitución, rehabilitación, satisfacción).

4 El universo de víctimas organizadas y no organizadas es amplio. En el Registro Único de Víctimas - RUV, con cierre a mayo de 2017, se había registrado un total de 8.048.252 personas que alegaron haber sido objeto de distintos hechos victimizantes con ocasión del conflicto armado, con corte a 1985. Esta cifra es indicativa de los importantes efectos de la confrontación armada, pero también de lo diversa que puede llegar a ser la elaboración de las memorias y los procesos de reivindicación de los derechos de las víctimas.

5 Cuando se habla de "iniciativas no oficiales de memoria" se habla de iniciativas de las víctimas y de ong y/o fundaciones que constituyen sus redes de apoyo.

6 Hay un debate acerca del reconocimiento de la existencia de víctimas de agentes del Estado en esta Ley. Para Cepeda (2013), la ley reconoce la victimización de todos los actores armados en la contienda, incluyendo al Estado, "luego de un proceso continuo de negación de esta realidad" (2013, p. 275); Rettberg, por su parte, señala que "el Artículo 3 de la ley reconoce como víctimas a hombres y mujeres, mayores de 18 años, que hayan sido afectados de forma directa por una violación al Derecho Internacional Humanitario (DIH), en el marco del conflicto armado (realizada por grupos armados ilegales y/o agentes del Estado) (...)” (2015, p. 185). Sin embargo, por otra vía de interpretación, Acebedo (2016) considera que en la Ley 1448, "el Estado continúa apareciendo como una institución protectora sin reconocimiento expreso de su participación en la violación del DIH, y lo que es más complicado aún, reitera a lo largo de la ley que no 'podrá presumirse o interpretarse el conocimiento de la responsabilidad del Estado [...] o sus 
acerca de aquello que posibilitó que los reclamos de las víctimas de la criminalidad estatal se instalaran en la agenda oficial de la negociación ${ }^{7}$.

Este artículo aporta una explicación hipotética a dicho interrogante, a partir del estudio del caso de la Fundación Manuel Cepeda Vargas para la Paz, la Justicia Social y la Cultura ${ }^{8}$ (FMCV), argumentando que:

[1] la introducción y consolidación de nuevos repertorios, que hicieron más efectiva la denuncia de los crímenes de Estado y la pedagogía social de la memoria histórica; y

[2] la dirección política que se imprimió a la reivindicación de los derechos humanos, para articularla con la solución política del conflicto armado, hicieron posible el posicionamiento de las víctimas de crímenes de Estado en el debate público y su reconocimiento, por vía de la acción criminal de agentes estatales, en el SIVJRNR pactado en el Acuerdo de Víctimas de La Habana.

Estas dos cuestiones han tomado cuerpo a través de prácticas culturales, que vehicularon las iniciativas no oficiales de memoria (GMH, 2009) (Briceño-Donn et al, 2009), y sus reclamos por verdad, justicia y reparación, y es lo que en este artículo se entiende como una política cultural (cultural politics) dirigida a la construcción de paz, y constituye su materia de análisis.

Desde el punto de vista metodológico, el estudio de caso contempló, en general, una revisión documental en prensa y archivos, la realización de entrevistas en profundidad, la revisión de la literatura académica producida por Claudia Girón Ortíz e Iván Cepeda Castro como directivos de la FMCV, y el registro de observación en eventos y espacios de discusión?.

agentes' (Ministerio del Interior y de Justicia, 2011, p. 22) por las violaciones a los derechos humanos" (2016, p. 220). Bello et al (2013) refuerza este último planteamiento cuando sostiene que una de sus principales contradicciones es la omisión por parte del Estado de su “agencia y participación en violaciones a los Derechos Humanos (...)” (2013, p. 246).

7 El segundo punto de la "Declaración de principios" que orientó la negociación de este Acuerdo parte del "reconocimiento de responsabilidad” por parte del Estado y las FARC-EP: “Cualquier discusión de este punto debe partir del reconocimiento de responsabilidad frente a las víctimas del conflicto. No vamos a intercambiar impunidades” (Mesa de conversaciones, 2016, p. 124).

8 La "Fundación Manuel Cepeda Vargas para la Paz, la Justicia Social y la Cultura” (FMCV), fue columna vertebral de tres experiencias centrales para el movimiento de víctimas de crímenes de Estado en Colombia, desde la década de 1990 hasta el presente: el "Proyecto Colombia Nunca Más” (PCNM), el “Movimiento de Víctimas de Crímenes de Estado” (Movice), y el “Costurero de la Memoria Kilómetros de Vida y de Memoria”.

9 Se analizaron documentos oficiales producidos en el marco de la transición de 1991 y la gestación de la Ley General de Cultura por el Departamento Nacional de Planeación (DNP), Colcultura, el Ministerio de Cultura y la Presidencia de la República, incluidos documentos no institucionales publicados por estas mismas dependencias. Se consultaron documentos (informes, resoluciones, sentencias) de la ONU, Unesco, la Corte IDH y la Sala de Justicia y Paz del Tribunal Superior del Distrito Judicial de Bogotá, y se hicieron registros etnográficos de algunas sesiones del "Costurero de la memoria", trabajo en el que se concentra hoy la FMCV. Para cotejar las percepciones individuales y grupales se realizaron entrevistas en profundidad a uno de los miembros fundadores de la FMCV, a activistas y defensores de derechos humanos, y a investigadores y académicos (políticas culturales, construcción de paz, justicia transicional, reparación, artes y derechos humanos). 


\section{Las iniciativas no oficiales de memoria como política cultural}

La unidad de análisis de las iniciativas no oficiales de memoria que ha propuesto el Grupo de Memoria Histórica (2009), entre las que incluye las de las víctimas de la criminalidad estatal, son los discursos, las representaciones, las prácticas y los significados que construyen las comunidades y organizaciones afectadas por la violencia con el fin de hacer público su dolor y denunciar las injusticias de las que han sido objeto.

Citando a Veena Das, estos discursos, representaciones, prácticas y significados son asumidos como "juegos de lenguaje" que constituyen formas de vida, "donde se definen los repertorios de posibles enunciados y acciones, mediante los cuales las personas enfrentan la diversidad"10 (GMH, 2009, p.19). Esto supone, como se sabe, una comunidad de lenguaje y significación, una cultura compartida.

Los medios de expresión equivalen a lo que Jelin ha denominado "vehículos de la memoria":"memoria que se produce en tanto haya sujetos que comparten una cultura" (2009, p.19). Los "vehículos de la memoria" pueden ser tanto libros como archivos u objetos conmemorativos, pero también expresiones y actuaciones "que antes que re-presentar el pasado, lo incorporan performativamente" (p.19). Esto nos saca de la esfera exclusiva de los textos culturales, y nos instala en las coordenadas de las prácticas de los sujetos y de los movimientos sociales, lo cual puede interpretarse como una política cultural, definida como:

la movilización de la cultura llevada a cabo por diferentes tipos de agentes -el Estado, los movimientos sociales, las industrias culturales, las instituciones tales como museos y organizaciones turísticas, asociaciones de artistas y otros - con fines de transformación estética, organizativa, política, económica y/o social. (Ochoa, 2003, p. 20)

Lo correspondiente a las prácticas políticas concretas de diseño e implementación de programas y proyectos específicamente relacionados con la movilización de lo simbólico pensado como expresiones artísticas (sea éste desde la "alta cultura", desde "la cultura popular" o desde "las industrias culturales"), patrimoniales, de difusión cultural, etc., sería algo parecido a lo que en inglés se llama cultural policy, o política pública cultural. Con Álvarez, Dagnino y Escobar (1999, 2001), se utiliza el concepto de cultural politics para llamar la atención sobre el "vínculo constitu-

La noción de repertorio refiere fundamentalmente a una práctica cultural. Taylor la define como los gestos, la performatividad, la oralidad, el movimiento, la danza y el canto, entre otras manifestaciones de las comunidades, y dice que son un tesoro de inventiva que les permite participar en la producción y reproducción de conocimiento por el solo hecho de hacer parte de su transmisión. Respecto del caso colombiano, siguiendo a Taylor, el GMH afirma que el "repertorio" da cuenta de "los relatos de los sobrevivientes, de la observación de sus prácticas y gestos, del reconocimiento de los traumas, de las reiteraciones y de los silencios, formas efímeras de conocimiento y de evidencia" (GMH, 2009, p.23). 
tivo" entre cultura y política, y sobre la redefinición de la política que esta visión implica. Este "lazo" o "vínculo constitutivo" significa que la cultura, "entendida como concepción del mundo y conjunto de significados que integran prácticas sociales, no puede ser comprendida adecuadamente sin la consideración de las relaciones de poder imbricadas con dichas prácticas" (Álvarez et al, 1999, p. 135).

\section{La política cultural de la Fundación Manuel Cepeda Vargas para la paz, la Justicia Social y la Cultura}

Manuel Cepeda Vargas fue el último Senador del movimiento político Unión Patriótica (UP). Fue asesinado el 9 de agosto de 1994 por efectivos del Ejército Nacional junto con paramilitares al mando de Carlos Castaño Gil, según pudo constatar la Corte IDH en sentencia condenatoria en contra del Estado colombiano (Corte IDH, 2010). De acuerdo con los archivos de la FMCV, con el Senador Cepeda, la UP contaba 2.444 militantes asesinados para la fecha, entre los cuales se contaban concejales, alcaldes, diputados, representantes a la Cámara y senadores de la República en ejercicio, candidatos presidenciales, dirigentes nacionales y militantes de base.

Según Claudia Girón, lo que impulsó la creación de la FMCV fue, por una parte, la necesidad de duelo personal, familiar, y por otra, un fuerte sentimiento de indignación por la indiferencia social y estatal frente a los recurrentes crímenes en contra de la oposición política. Se registró como una ONG dedicada a la defensa y la promoción de los derechos humanos, en cuyos principios se suscribía "la independencia, la autogestión y el trabajo en red", enfocado en el desarrollo de una estrategia orientada a la pedagogía social de la memoria histórica (Barrero, 2010; Cepeda \& Girón, 2005). Desde esa óptica, la FMCV se creó con el fin de denunciar la impunidad de los crímenes de Estado y dignificar la memoria de sus víctimas "producidas en el marco del conflicto armado, la guerra sucia contra la oposición política, la limpieza social y la guerra contra las drogas" (Cepeda \& Girón, 1998, 2004).

Como generación de jóvenes en los años 90 fuimos marcados por el asesinato de cuatro candidatos a la Presidencia de la República: Luis Carlos Galán, Carlos Pizarro, Bernardo Jaramillo y Jaime Pardo Leal. De esos cuatro candidatos, el Estado solamente rescató la memoria de Luis Carlos Galán, a quien honró con un monumento en el Concejo de Bogotá. El homenaje a los otros tres candidatos asesinados y negados por la historia oficial fue promovido durante décadas por los defensores de los derechos humanos y los familiares y copartidarios (Entrevista a Claudia Girón, agosto 18 de 2016, en adelante: Entrevista C.G., 2016a). 
Los referentes inmediatos de la FMCV vienen de dos contextos: primero, el de las transiciones de la dictadura a la democracia en el Cono Sur, fundamentalmente sus experiencias de documentación de las violaciones a los DDHH y la movilización como estrategia de presión política y social para exigir justicia; y segundo, en el ámbito nacional, la estrategia de las organizaciones que hicieron frente al Estatuto de Seguridad del gobierno de Julio César Turbay Ayala, consistente en la construcción de redes trasnacionales de presión ${ }^{11}$ para levantar el Estado de sitio, derogar el Estatuto, liberar a los presos políticos y aceptar la vigilancia de las organizaciones internacionales de DDHH. Estos referentes configurarán el horizonte estratégico de la FMCV y del movimiento de víctimas de crímenes de Estado durante la segunda mitad de la década de 1990 y la década del 2000 (Gómez, 2015; Pedraza \& Álvarez, 2016). Así mismo, otras organizaciones y plataformas como la Asociación de Familiares de Detenidos y Desaparecidos, ASFADDES, y el Tribunal Permanente de los Pueblos, sirvieron de referentes para la FMCV.

Pese a que "el tema de la memoria era trabajado fuerte por ASFADDES, advierte Girón, fue la Fundación la que llegó a hacer cosas estéticas, en medio de organizaciones de abogados que solo pensaban jurídicamente. La Fundación aportó color, irreverencia" (Entrevista a Claudia Girón, septiembre 1 de 2016, en adelante: Entrevista C.G, 2016b). El "color y la irreverencia", y la opción por lo "estético", fue lo que les abrió un espacio en el mundo de los derechos humanos, copado por ONGs que para mitad de la década de 1990 contaban con gran trayectoria y reconocimiento.

Asumimos entonces como método de trabajo, la pedagogía social de los derechos humanos como herramienta para desmarginalizar las experiencias de la guerra. En esa dirección, la primera posibilidad que exploramos fue la de sensibilizar a la opinión pública a través de diferentes expresiones artísticas. La música contemporánea -el rock y el rap- tal vez sería un lenguaje más adecuado para "hablar" a las generaciones jóvenes acerca de la memoria de la últimas cinco décadas del conflicto armado en Colombia. Con la colaboración de un grupo de estudiantes que trabajaban en un programa de radio universitaria, elaboramos montajes musicales y de radioteatro sobre la cuestión de si los hechos históricos de la violencia en Colombia deben ser recordados u olvidados. (Cepeda \& Girón, 2005a, p. 9)

11 Se trata del denominado "efecto bumerán" (Risse y Sikkink, 1999): “frente a violaciones sistemáticas a los derechos humanos, los grupos domésticos en oposición no pueden obtener garantías por parte de su Estado, por lo que no enfocan sus acciones de denuncia hacia éste sino que buscan directamente una conexión con actores internacionales. El objetivo de estas acciones es encontrar aliados internacionales que se unan a la actividad de oposición, y que el Estado sea presionado a aceptar sus demandas" (citado en Bitar, 2007, p. 10). 
Optar por formas "menos duras" de denuncia les significó pronto fuertes tensiones e incluso rupturas con los sectores más sectarios y ortodoxos de la izquierda política, "que vieron de manera despectiva y la mejor de las veces diminutiva el hecho de que con 'pinturitas', 'obritas', y 'carnavales', los 'compañeros' de la FMCV confrontaran al establecimiento y elaboraran la memoria de los militantes de la UP” (Entrevista a Juan Pablo Aranguren, 16 de septiembre de 2016, en adelante: Entrevista J.P.A., 2016).

Mientras que desde esos sectores se seguía animando la confrontación, la consigna y la denuncia directa y descarnada, que convocaba "al verdadero compromiso político con el movimiento" (Entrevista J.P.A., 2016), la apuesta de la FMCV, según Claudia Girón, fue "humanizar a los muertos":

Nosotros queríamos mostrarle a la gente quiénes eran los asesinados, queríamos que se conociera su lado humano, y no solamente que eran unos políticos de izquierda. Queríamos que la gente se preguntara qué implica la muerte de los otros, y para eso los mejores aliados que encontramos fueron el arte y la cultura. Contra la fetichización de la memoria, nosotros queríamos mostrar la vida cotidiana de las víctimas. Esa era la única forma que concebimos de hacer memoria colectiva, de cuestionar a la gente sobre la gravedad de lo sucedido y sobre todo de hacerla caer en cuenta por qué se recordaba más a unos que a otros (...) Entonces la pregunta es cómo hacemos memoria colectiva y cómo empezamos a ver esa memoria fragmentada en clave de territorio común. Ylo primero que hicimos fue teatro, juegos, preguntas, trabajos de memoria con jóvenes y viejos, ejercicios pedagógicos, lúdica, todo desde la cultura y el arte para ver qué cosas la gente recordaba y por qué. (Entrevista C.G., 2016a)

Los repertorios de la FMCV, desde 1994 hasta el 2000, se pueden definir por la caracterización anterior: conciertos, montajes musicales y radioteatro, vídeos y teatro experimental, galerías de la memoria ${ }^{12}$, cenas y tertulias, muestras colectivas de artistas, museos rodantes (bus de la memoria), seminarios, conversatorios e investigaciones (Tabla 1).

12 En uno de sus artículos académicos, describen la experiencia de la Galería de la siguiente manera: "En el marco de esta experiencia itinerante de socialización, cada familia o grupo de personas próximas a las víctimas, se encarga de traer objetos, documentos e imágenes pertenecientes a los ausentes. Los objetos conmemorativos permiten mostrar al público presente quién era la persona asesinada, qué le gustaba hacer, cuáles eran sus sueños y, en fin, cuál era su proyecto de vida. Se trata de exposiciones o instalaciones nómadas, después de las cuales, cada familia se lleva consigo los materiales que aportó para el evento.

Durante las galerías, cada familiar de las víctimas tiene un espacio y un momento para compartir su testimonio, y cada cual puede hablar a su manera. En estos relatos se presentan los hechos que dan cuenta del contexto de victimización, del recorrido que se ha hecho para la búsqueda de la justicia, o de las condiciones que han producido la impunidad en cada caso concreto. En la medida de lo posible, se aportan argumentos relativos a la responsabilidad de los actos criminales. 


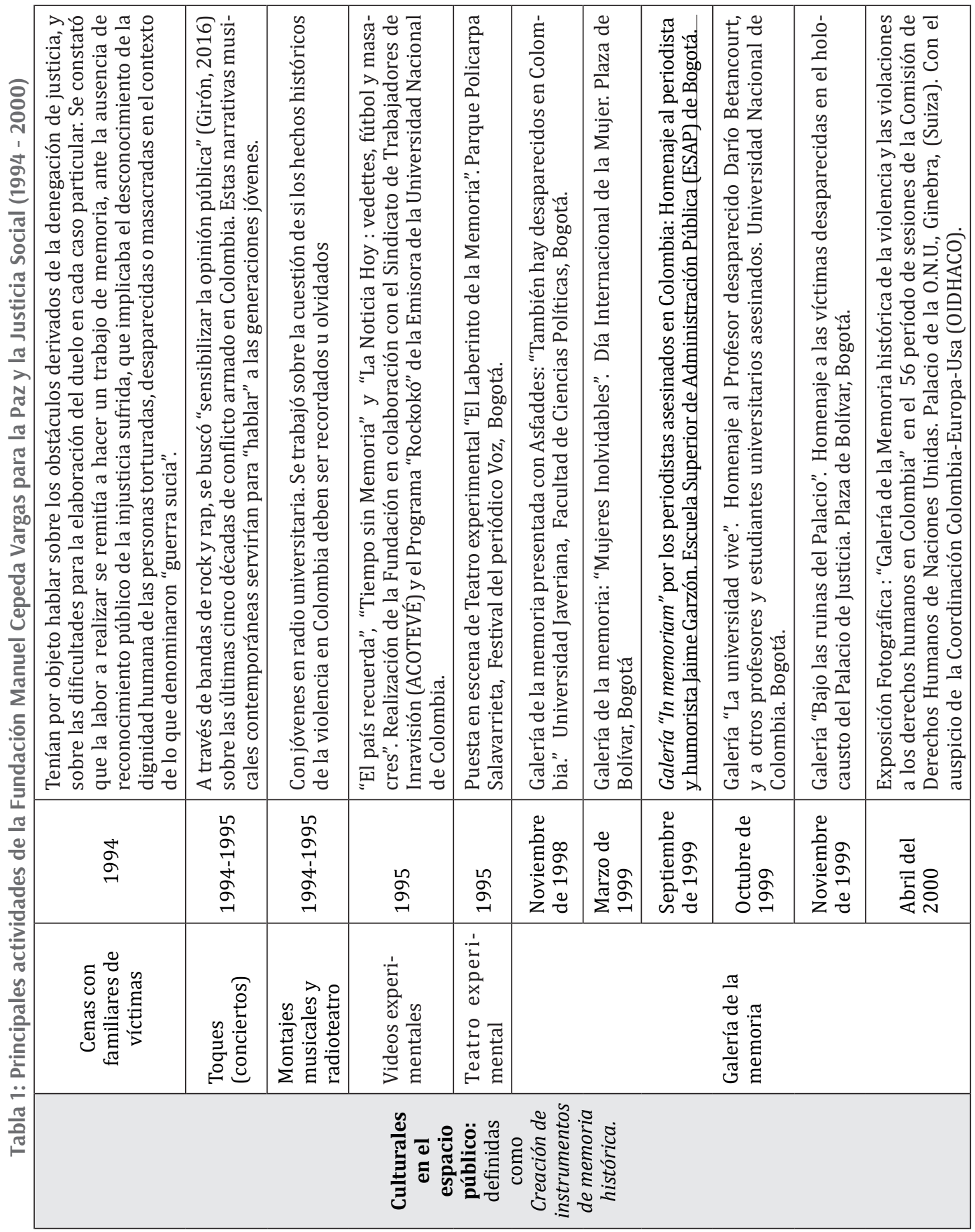


Andrés Tafur Villarreal

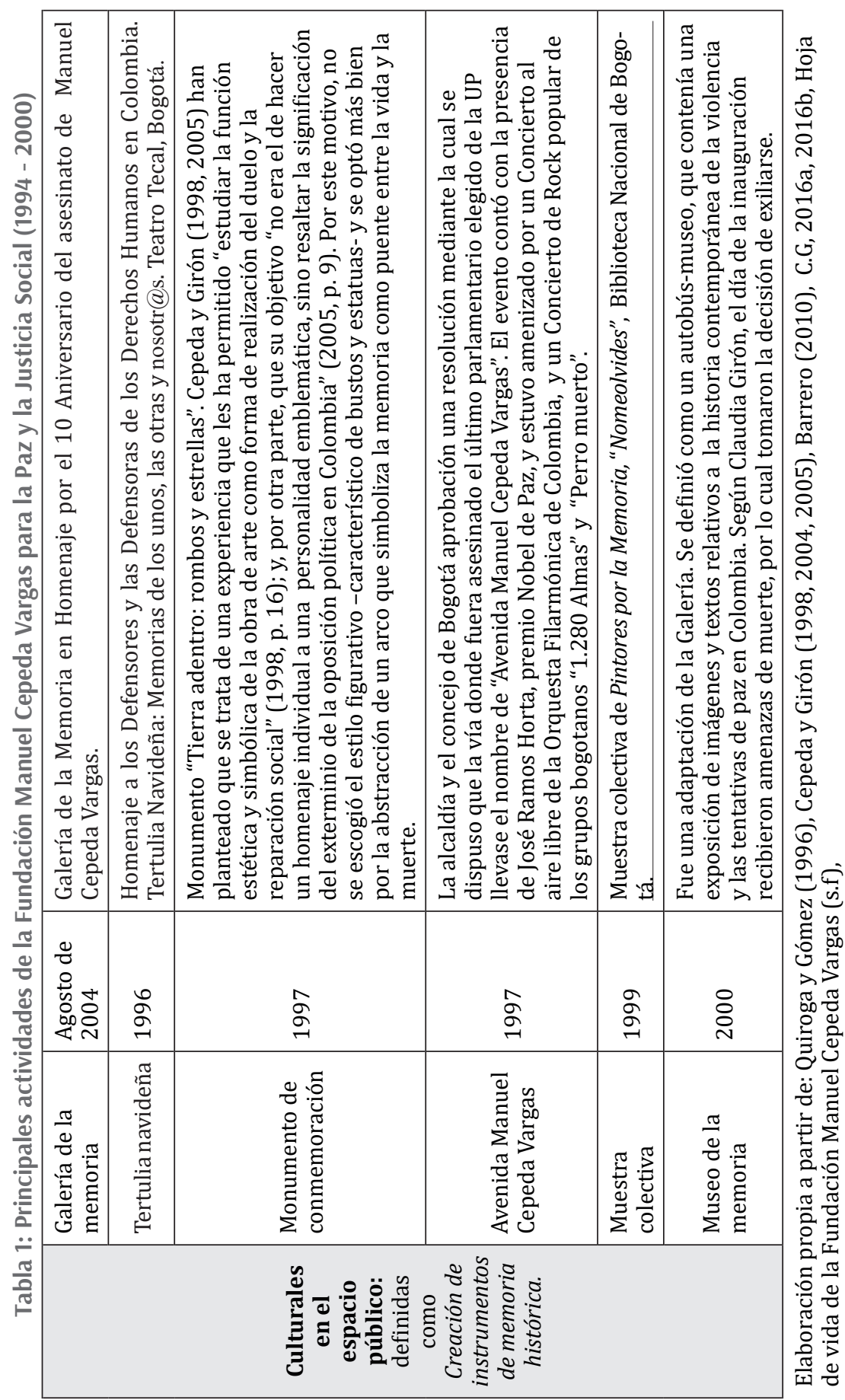




\section{El PCNM, el Movice y el Costurero de la memoria}

La Fundación, junto con otras 16 organizaciones defensoras de derechos humanos, conformaron el 10 de abril de 1995 el "Proyecto Colombia Nunca Más" (PCNM), una plataforma nacional que se propuso sistematizar, documentar y denunciar las violaciones de derechos humanos por parte del Estado colombiano y los paramilitares ${ }^{13}$. El PCNM tuvo dos antecedentes: la campaña denominada "Colombia Derechos Humanos", que denunció "nacional e internacionalmente las violaciones a los Derechos Humanos y la impunidad existentes en el país hasta el momento" (GMH, 2009, p. 175); y el "Seminario Internacional sobre Comisiones de la Verdad", realizado en Bogotá el 8 y 9 de junio de 1994. El escepticismo ante "la falta de eficacia de las comisiones gubernamentales, llamadas de la verdad, frente al problema de la impunidad en América Latina (...)” (2009, p. 175) y preocupados por "algunas circunstancias que hacían presumir alguna posibilidad de convocatoria a una eventual Comisión de Verdad para el caso colombiano" (PCNM, 2016) hizo que los grupos de defensores se adelantaran a conformar un grupo independiente que encara la labor de recolección de información de los crímenes de Estado.

En tal sentido, a las organizaciones sociales les asistían preocupaciones tales como la necesidad de hacer una documentación exhaustiva de los casos de Crímenes de Lesa Humanidad, las condiciones creadas desde las instancias del Estado para que no fuera posible la realiza-

\footnotetext{
En las primeras galerías se propuso a los familiares llenar fichas con esta información y aportar una pequeña fotografía de las víctimas, con el fin de contribuir a alimentar las bases de datos ya existentes en otras organizaciones de derechos humanos. El proyecto no fue pensado ni como un espacio terapéutico, ni tampoco como un mecanismo de denuncia, ni menos aún, como un lugar de culto a las víctimas; era más bien un trabajo guiado por una intención de compartir y de poner en contexto la memoria. La "Galería" fue concebida como un instrumento destinado, no a hablar exclusivamente de la muerte, sino de la vida detrás de los rostros y los nombres; de aquello que representaban las personas para su entorno social, de lo que significaban sus ideas, que de una u otra manera continúan viviendo a través de otros.
}

En esas primeras galerías, vimos que muchos de los familiares de las víctimas encontraban por primera vez un espacio propicio para compartir su relato. La experiencia de la impunidad y el fracaso de las tentativas de acceso a la justicia habían desestimulado su disposición a hablar y a participar en público. En algunos casos, la imposición prolongada del silencio había sembrado la desesperanza y la resignación, en un contexto donde las leyes -formalmente hablando - están por todas partes, pero los derechos son invisibles y su protección se queda en el plano virtual. El trabajo debía centrarse en promover "la toma de la palabra" y en provocar una experiencia innovadora: la acción participativa de los sujetos sociales dirigida a visibilizar públicamente la impunidad, rebasando los esquemas que atribuyen "lugares habituales" a las víctimas y a los victimarios.

El impacto público de la "Galería de la memoria" era fuerte, pues consistía en un encuentro vivo con la historia de la violencia y con testimonios de actualidad sobre los acontecimientos recientes del conflicto armado. Dicho encuentro, muy pluralista, posibilitó la instauración de un diálogo abierto sobre los sujetos y objetos de la memoria nacional. Logramos reunir a miembros de las familias de personajes muy conocidos con familiares de víctimas menos conocidas o anónimas. Había familiares de sindicalistas, de profesores universitarios, de estudiantes, de periodistas, de magistrados y fiscales, de abogados, de líderes o activistas políticos, asesinados en los últimos 50 años, y cuyos casos permanecían en el olvido (Cepeda \& Girón, 2005a, p. 10, 11).

13 El PCNM ha logrado documentar información de más de 41.000 víctimas de torturas, desaparición forzada y/o ejecución extrajudicial en todo el país, que se encuentran disponibles en la base de datos del Movice. 
ción de investigaciones sobre estos crímenes y la posible negociación con los grupos insurgentes del conflicto político militar que vive el país. Los organismos de derechos humanos valoraban que de ser convocada una Comisión de Verdad, sería imposible que lograra resultados conducentes a la disminución de la impunidad, al castigo a los victimarios de lesa humanidad. (PCNM, 2016)

Dentro del PCNM, la Fundación se concentró en lo estético y lo pedagógico, gracias al lenguaje "fresco y renovador" que asumió como principio. Claudia Girón define el PCNM como una apuesta de trabajo en red, a la que la Fundación se articuló tras el trabajo que otras organizaciones venían haciendo, y como una experiencia de investigación-acción participativa que avanzó en un trabajo silencioso de recolección de información, estratégico dado al alto riesgo que suponía hacer denuncia pública de violaciones a los Derechos Humanos para la época.

El archivo del PCNM entró a hacer parte de la documentación del Movice, que bajo la atribución de crímenes de Estado y frente a la coyuntura que generó en Colombia la Ley 975/2005 o Ley de Justicia y Paz, surgió ese mismo año como el Movimiento de Víctimas de Crímenes de Estado, conformado por 300 organizaciones de la sociedad civil (Movice, 2016). De manera comprensible, la aprobación de la ley constituyó un evento determinante en el cual las organizaciones de víctimas posicionaron sus agendas de reivindicación y establecieron nuevas estrategias y alianzas políticas para redireccionar y cualificar sus luchas y reclamos.

El Movice, en términos de Mosquera (2015), se presentó en ese contexto "como un contrapoder a la institucionalidad de Justicia y Paz, a su manera de ver la justicia, la verdad y la memoria principalmente" (p. 215). Se trató, en términos de Girón y Vidales (2010) de un trabajo de "reconstrucción de memorias colectivas" que se propuso "propiciar una experiencia activa de empoderamiento de las víctimas como sujetos morales de derecho a partir de la verdad, la justicia y la reparación" (p. 252), a través de dos herramientas fundamentalmente: las Galerías de la Memoria y las Audiencias Ciudadanas por la Verdad ${ }^{14}$.

La Fundación conformó el comité de impulso nacional del Movice y asumió su vocería pública a través de Iván Cepeda.

Cuando entramos a hacer parte, ya no del PCNM sino del Movice, producto del PCNM, era casi clandestino hacer memoria, era muy peligroso. Pero cuando emerge esa Ley de Justicia y Paz todo se dio para que nosotros nos visibilizáramos como un colectivo, como un

14 Las audiencias consistieron en una serie de eventos desarrollados por el Comité de Impulso Nacional del Movice y sus capítulos regionales en distintas zonas del país, con el fin de socializar las estrategias del movimiento, y de investigar y denunciar públicamente lo sucedido durante el desarrollo de atrocidades masivas, en su período previo y posterior. 
sujeto político colectivo, y emergiera la voz duro para decir acá hay crímenes de Estado y eso recayó sobre Iván y él se convirtió en el vocero nacional (...) Lo que hicimos fue rápidamente posicionar al Movice como un actor político colectivo y empezar a mostrar todo el trabajo de memoria. Lo que hicimos fue interpelar la ley y la negociación con los paramilitares porque ellos no eran un tercer actor en conflicto. Ellos eran cómplices del Estado y el gobierno negoció con ellos como si ellos fueran insurgentes. Entonces nosotros fuimos una voz impactante ahí. Al principio nos veían como gente muy radical y fundamentalista, y nosotros fuimos muy maximalistas en la exigencia de verdad, justicia y reparación, que ya veníamos trabajando desde antes pero con la jerga transicional se posicionó ese lenguaje ya mucho más colectivamente. Entonces nosotros decíamos "toda la verdad, toda la justicia, toda la reparación" sabiendo que eso no es posible, pero tratando de que la cosa no se fuera de agache. Si nosotros no somos maximalistas en términos de empujar y de denunciar, a pesar de que seguíamos invisibilizados y seguían matando, no hubiéramos logrado que se reconociera que en Colombia había crímenes de Estado, porque en Colombia eso no se reconocía. Se voltea siempre el foco para enfatizar en lo que la guerrilla hizo. Nosotros siempre trabajamos visibilizando eso, pero visibilizando la dignidad de las víctimas, y lo simbólico para nosotros fue tratar de ver el sujeto de derecho que hay detrás de cada una de las muertes y las desapariciones, qué derechos se violaron y cuáles fueron vulnerados, y por qué eso nos atañe. No ha sido fácil porque siempre ha habido una estigmatización muy grande pero nosotros logramos posicionar la memoria como un derecho. (Entrevistas C.G., 2016a, 2016b)

Claudia Girón asumió el liderazgo de la Fundación en 2010, y en articulación con una plataforma de ONGs nacionales e internacionales fundó el "Costurero de la Memoria Kilómetros de Vida y de Memoria" inicialmente con las familias de los "jóvenes de Soacha”, asesinados a sangre fría por efectivos del Ejército Nacional y luego presentados como bajas en combate ${ }^{15}$. En el 2013 este proyecto se amplió hacia otros sectores y organizaciones de víctimas del conflicto político, social y armado, y se articuló al Proyecto de "Los Oficios de la Memoria” promovido por el Centro de Memoria, Paz y Reconciliación Distrital de Bogotá. Desde esa fecha los familiares de las víctimas se reúnen todos los jueves a tejer, en dos sentidos: en

15 Se ha difundido la expresión "Falsos positivos" para referirse a esta práctica, tanto en medios de comunicación como en la jerga política. Human Right Watch (2015) estima que entre 2002 y 2008, la ejecución de civiles por brigadas del Ejército fue una práctica habitual en toda Colombia. Soldados y oficiales, presionados por superiores para que demostraran resultados "positivos" e incrementaran el número de bajas en la guerra contra la guerrilla, se llevaban por la fuerza a sus víctimas o las citaban en parajes remotos con promesas falsas, como ofertas de empleo, para luego asesinarlas, colocar armas junto a los cuerpos e informar que se trataba de combatientes enemigos muertos en enfrentamientos. 
uno literal, en tanto quieren constituirse en un espacio autosostenible, que pueda mantenerse y dar opciones de empleo a sus participantes a través de su propia producción de tejidos, ropa, adornos, etc., y en uno simbólico, en tanto que el tejer es al mismo tiempo lo que los repara y da sentido a la vida y a la resistencia por la verdad y la justicia. "Es tejer a mano y poco a poco, posibilidades de incidir en lo pequeño pero también en lo grande" (Entrevista C.G., 2016a).

Lo que más le llamó la atención, según Claudia Girón, fue que los "falsos positivos" causaron gran indignación en la opinión pública nacional e internacional, contrario a otras víctimas de crímenes de Estado, lo cual no haría más que confirmar su tesis de "la segregación de las víctimas de la violencia política" (Cepeda \& Girón, 2005).

Cuando una víctima es de la UP no es tan inocente, pero no pasa así con los "falsos positivos". Nosotros empezamos con esa curiosidad, por qué la gente se toca tanto con lo de los "falsos positivos", pues porque ellos sí son inocentes, la otra gente no era inocente, entonces lo que nosotros empezamos a hacer fue un trabajo de memoria con ellos, y luego empezamos a involucrar poco a poco gente de otros colectivos, gente del Movice, gente desplazada, luego incorporamos a desplazados de la guerrilla, no solo víctimas de crímenes de Estado. (Entrevista C.G, 2016a)

\section{Análisis de los datos}

La política cultural de las víctimas de crímenes de Estado: poner el cuerpo en escena

Lo cultural en las estrategias de resistencia y de denuncia de la FMCV revelan un "espíritu de época", un espíritu que se emparenta con lo que Sarlo (2005) ha denominado el "Giro subjetivo" de la memoria. Este giro supone que las reivindicaciones ya no están centradas en el movimiento social sino en el sujeto. Esto se expresa en las actividades realizadas para "salvaguardar" la memoria: "ligadas a las autobiografías, a los datos de cada uno, a los objetos personales, en suma, a no dejar que los individuos se diluyan en el movimiento social, y de esto está marcada la época" (Entrevista J.P.A., 2016).

Esas prácticas y discursos provocaron, como ya se dijo, tensiones y fracturas tanto con la izquierda ortodoxa como con las organizaciones de derechos humanos más antiguas, cuyas formas y retóricas privilegiaban la exposición excesiva del horror y el compromiso heroico, al tiempo que negaban el dolor y las emociones, reivindicando cierto sentimiento martirológico. Se trata, en términos de Diana Gómez, de un "habitus emocional hegemónico" que le dio paso a nuevos repertorios 
para realizar la denuncia, que pusieron la vida en el centro de los discursos y las representaciones. "Yo sí creo que luego hay un peso mucho más grande del cuerpo, de la música, de lo cultural, de lo artístico, y de la subjetividad. Yo creo que en todas esas nuevas formas de protesta entran esos elementos, y las emociones" (Entrevista a Diana Gómez, 25 de octubre de 2016, en adelante: Entrevista D.G., 2016).

Que se trató de un "espíritu de época" que afectó al movimiento social en general y al movimiento de víctimas y de defensores de derechos humanos en particular, da cuenta Acebedo (2016) en su trabajo sobre las víctimas de Estado en Colombia. Para esta autora, la década de los ochenta fue rica en cuanto a la proliferación de movimientos sociales que no se autoafirmaron solo a partir de su condición de clase o conciencia obrera, que modificaron los repertorios tradicionales de la protesta, así como sus actores. Los movimientos que emergieron durante la época, como el movimiento feminista, los ambientalistas, las minorías étnicas o las expresiones en pro de la diversidad sexual, "incorporaron en sus demandas cuestiones relacionadas con la identidad más allá de la clase, sacando de las sombras las cuestiones culturales y subjetivas que estaban recluidas en el ámbito de lo privado (...)" (Acebedo, 2016, p. 208).

El movimiento de derechos humanos, por su parte, osciló entre "la denuncia de los crímenes cometidos por el Estado como abuso de poder" (...) "la defensa de la vida como sustento primario de la realización material humana, y (...)” la defensa y reivindicación del "derecho a la participación política” (p. 209), lo cual abrió el camino para la "recuperación de las historias de vida, las fuentes orales y los testimonios por sus aportes para la construcción tanto de las historias nacionales como para las memorias colectivas" (Acebedo, 2016, p. 210). En el centro de esta cuestión siempre estuvo presente la disputa por el sentido que se le otorgaba al pasado, pasado que, desde el punto de vista del movimiento, se encuentra estrechamente ligado a la identidad de la víctima y, por consiguiente, a su repertorio de acción.

Esto es de muchas maneras expresado por Claudia Girón, para quien el ejercicio de una pedagogía social de la memoria histórica pasaba necesariamente por transformaciones en los repertorios y en los auditorios, lo cual abrió una ventana de oportunidad a la lucha por los derechos humanos, al tiempo que dejó un legado para las nuevas generaciones.

Así lo ve José Antequera, miembro de "Hijos e Hijas por la memoria y contra la impunidad", para quien el liderazgo de Claudia Girón e Iván Cepeda "hizo escuela" en la defensa de los derechos humanos y en las luchas por la memoria de las víctimas de la criminalidad estatal.

Yo creo que no es solo con una ruptura con una parte del movimiento de DDHH, es una ruptura con la izquierda en general, es una ruptura con formas de expresar de la izquierda, es una ruptura que le da valor al reconocimiento de las víctimas no como una mera cuestión de denuncia sino 
como un acto que activa otro diálogo con la sociedad, y así le da mayor fortaleza a la denuncia. (...) se trata de una visión muy de apertura en términos de las formas, pero hay una comprensión política interesante sobre cómo se concibe la lucha por los ddhh como una lucha política, no como una lucha meramente reivindicativa. (Entrevista a José Antequera, noviembre 10 de 2016, en adelante: Entrevista J.A, 2016)

Para José Antequera, en suma, las prácticas y los discursos renovadores de la FMCV supieron interpretar muy bien los cambios históricos, y esa es la razón por la cual rápidamente se convirtió, por un lado, en un referente de liderazgo al pie de organizaciones como Reiniciar o la Comisión Colombiana de Juristas, que llevaban varios años en la defensa de los derechos humanos, y por el otro, logró posicionar la reivindicación de las víctimas de crímenes de Estado en las coordenadas de la opinión pública.

Esto último, a juicio de Diana Gómez, vocera nacional del Movice y miembro de Hijos e Hijas, "es uno de los más grandes triunfos de las víctimas de crímenes de Estado":

Y yo creo que los nuevos repertorios de lucha sí sirvieron para eso, yo
creo que eso ha hecho más fácil la comunicación con la sociedad. Quizás
menos confrontativa a veces, quizás también menos dolorosa (...). En-
tonces yo sí creo que uno de los grandes logros del Movice ha sido eso:
yo creo que se comunica más con la sociedad. Y en eso las galerías son
muy interesantes, porque a la gente el rostro le impacta. Porque le da
humanidad a esas personas que creemos que no son inocentes. Impacta
mucho: las personas se acercan mucho a las galerías, se acerca a pregun-
tar, o no pregunta y lee y se va. Yo creo que eso sí es un logro importante
que implica un cambio cultural. (Entrevista D.G., 2016)

\section{Criminalidad estatal y solución política del conflicto armado}

El activismo de la FMCV no se puede entender al margen de un direccionamiento político en la lucha por los derechos humanos y la reivindicación de la memoria, la verdad, la justicia y la reparación, en perspectiva de la solución política del conflicto armado. Dicho de otra manera: que la defensa de los derechos humanos por parte de la FMCV debe verse al mismo tiempo como parte de una lucha política por la terminación negociada del conflicto armado.

Ese planteamiento ha sido expresado desde las primeras elaboraciones académicas de Iván Cepeda y Claudia Girón, en 1998:

La reflexión sobre memoria y reparación debe ser una preocupación permanente, objeto de acciones continuas dentro de la vida social, pero cuando esa acción y ese pensamiento se inscriben dentro de los 
grandes temas de una agenda de solución política del conflicto armado en Colombia, adquieren, como vemos, una importancia especial. (...) Es necesario que en la agenda de negociación del conflicto se discutan asuntos como la creación de mecanismos legales y jurídicos que permitan el acceso a los archivos oficiales y el pleno acceso a la información, la constitución de una Comisión de la Verdad, la modificación sustancial del fuero militar, el cambio radical de la naturaleza y funciones de la Fuerza Pública, la erradicación definitiva de la doctrina de Seguridad Interna, la formulación de mecanismos de penalización efectiva de las violaciones a los derechos humanos y de los crímenes de lesa humanidad, la institución de formas de reparación integral para las personas en situación de desplazamiento y para quienes han sido afectados por delitos como la desaparición forzada, el genocidio y la tortura. Somos una sociedad que no conoce la memoria histórica de sus acontecimientos más traumáticos, ni la justicia frente a los crímenes de lesa humanidad, que no ha realizado nunca el duelo colectivo. A esos vacíos éticos y de justicia debe responder un proceso que busque la solución auténtica del conflicto armado y la democratización del país. (Cepeda \& Girón, 1998)

En otro artículo, publicado en Francia, escrito desde el exilio en el 2003, afirmaban:

En este contexto [primer año de la presidencia de Álvaro Uribe Vélez], la Fundación que nosotros dirigimos consagra hoy sus esfuerzos a la oposición al proceso de afianzamiento de la impunidad de los crímenes contra la humanidad, y a las acciones que contribuyan a obtener el apoyo estratégico de la comunidad internacional para la solución política del conflicto armado. Consideramos que, a pesar de sus complejidades, la violencia de larga duración que padece Colombia sigue teniendo hondas raíces socio-políticas. La superación de esa espiral de violencia tiene que ser, en consecuencia, el resultado de un proceso de entendimiento y diálogo político entre el Estado y los grupos guerrilleros. Por eso es imprescindible estimular la solución negociada entre las partes en conflicto, e incentivar toda oportunidad que conduzca a acercamientos y acuerdos parciales o globales de carácter humanitario. (Cepeda \& Girón, 2005a)

Esto evidencia, en concreto, el convencimiento de que no solamente las transformaciones estructurales y la democratización de la sociedad pasan por la solución negociada del conflicto armado, a juicio de la FMCV, sino que el fin de la guerra es condición sine qua non para que se dé un verdadero debate público sobre los crímenes del pasado (Cepeda \& Girón, 2005b).

Y eso es precisamente lo que no ocurrió durante el proceso de paz adelantado con los paramilitares, el cual la FMCV se negó a reconocer como una transición 
genuina de la guerra a la paz. El argumento apunta a que mientras no existan las condiciones que garanticen el cumplimiento y la protección de los derechos, y, por ende, no existan las bases sociales sólidas que contribuyan a la no repetición de los hechos atroces, no habrá ninguna posibilidad de llevar a cabo procesos exitosos de recuperación y apropiación crítica de la memoria histórica de los acontecimientos ocurridos con ocasión del conflicto armado. Un argumento que comparten con otros académicos ${ }^{16}$.

Esto tiene que ver con el asunto central en la reivindicación de la FMCV y de los emprendimientos colectivos ${ }^{17}$ de los que ha hecho parte a lo largo de su proceso en la defensa de los derechos humanos: la victimización por parte de agentes estatales, los crímenes de Estado.

Hablar de "crímenes de Estado" significó en principio una ruptura dentro de la izquierda, que durante mucho tiempo concibió, bajo el concepto de guerra sucia, que los asesinatos de no combatientes se ajustaban de cierta manera a la dinámica de la lucha política. Esperando la revolución, "a la vuelta de la esquina", muchos militantes de la izquierda asumieron la muerte como un deber, en una narrativa que no pocas veces convirtió a los mártires en héroes, y al mismo tiempo motores de la lucha política e incluso, como ha señalado Dudley (2008), justificación para continuar y recrudecer la lucha armada. Entonces, hablar de los asesinatos selectivos como crímenes de Estado y no como el "producto" de la lucha política (en armas), ponía en primer plano su carácter injusto, asumido como una cuestión que no tenía por qué pasar en el marco de la democracia. Eso supuso una ruptura con quienes nunca aceptaron esas conclusiones.

Según Antequera, en medio de ese debate, Iván Cepeda, quien hizo parte del sector del Partido Comunista que se distanció de la tesis de la Combinación de todas las formas de lucha, y Claudia Girón, quien no tuvo militancia política con la izquierda, asumieron la lucha por la solución política del conflicto como parte de la reivindicación contra la criminalidad estatal, "por razones históricas y políticas", que permiten entender el papel que ha jugado el mismo Cepeda en el proceso de paz entre el Estado colombiano y la guerrilla de las FARC-EP.

Una razón histórica evidente es que parte de los crímenes de Estado se han destinado a asesinar líderes de la lucha por la solución política. Parte de los crímenes de Estado ha tenido como fin evitar la apertura democrática, y el mero proceso de paz que para muchos es una bo-

16 Ver Uprinmy \& Saffon (2006, 2009), CNMH (2009), Giron \& Silva (2010), Orozco (2009), Aranguren (2012), Bello et al (2013).

17 De estos emprendimientos se cuentan el Proyecto Colombia Nunca Más (PCNM), el Movimiento de Víctimas de Crímenes de Estado (Movice) y el Costurero de la Memoria Kilómetros de Vida. Sobre la relación de la FMCV con estas plataformas ver (Tafur V., 2016). 
bada, pero parte de los crímenes de Estado han estado ligados a eso, por las implicaciones que eso tiene. Y segundo una lucha política en particular, porque dentro del acuerdo se incluyen unos elementos de justicia transicional que al incluirse y al abarcar a agentes del Estado permiten avanzar en la reivindicación de los crímenes de Estado. La Comisión de la Verdad, la Jurisdicción Especial para la Paz, la búsqueda de personas desaparecidas, son mecanismos que permiten romper la afirmación dada por sentada de que la guerrilla es la única responsable de todos los crímenes del país y que el Estado es un actor neutral. Se plantea entonces unos mecanismos que tengan como destino investigar y clarificar cosas, entre esos los crímenes de Estado que nosotros reivindicamos. (Entrevista J.A., 2016)

\section{Conclusiones: la defensa de los derechos humanos como una lucha política}

La Fundación nació tras un acontecimiento traumático, el asesinato del último Senador del movimiento político Unión Patriótica, Manuel Cepeda Vargas. Sus gestores, un grupo de familiares y amigos del Senador bajo el liderazgo de Iván Cepeda Castro y Claudia Girón Ortíz, reaccionaron a la impunidad en que se mantenían los asesinatos sistemáticos en contra de los militantes de la UP, que para la época superaba los 2.400 casos, y a la generalizada indiferencia social y estatal respecto de la memoria y la dignidad de estas víctimas.

Su activismo por la defensa de los derechos humanos y la reivindicación de la memoria tuvo como principio el trabajo en red. Esta disposición la condujo a la articulación con otras organizaciones y movimientos que le permitieron posicionarse al interior de la "familia humanitaria" nacional e internacional, y actuar estratégicamente en su lucha en contra de la impunidad. El PCNM, el Movice y el Costurero de la Memoria son producto de esas alianzas estratégicas, cada una en distintos momentos de lo que abiertamente se puede interpretar como una lucha política.

El PCNM fue el resultado de un momento crítico en la defensa de los derechos humanos en Colombia, en el que, por seguridad personal y animados por la posibilidad de que se creara una Comisión de la Verdad en Colombia, los defensores se dedicaron a registrar, documentar y sistematizar en un archivo las violaciones a los derechos humanos por parte de agentes estatales y de grupos paramilitares. Tras diez años de ese proceso, ante la posibilidad de que el Estado no satisficiera los derechos de las víctimas en el marco del proceso de negociación abierto con los grupos paramilitares, el Movice surgió como una plataforma de articulación y de movilización local, regional y nacional, que posicionó a las víctimas de la criminalidad estatal como un actor político, aunque sin mayor reconocimiento jurídico. Ni la Ley de Justicia y Paz ni la Ley de Víctimas y Restitución de Tierras, reconocieron a los agentes estatales como un actor del conflicto armado, ni al Estado colombiano como partícipe de las violaciones a los derechos humanos o al DIH. 
Tras la constante movilización y denuncia de los hechos victimizantes, el acto de perdón público a que fue obligado el Estado colombiano por el magnicidio del Senador Manuel Cepeda Vargas (Corte IDH, 2010) y las atrocidades reveladas progresivamente por lo que en la opinión pública se denominó como "Falsos positivos", las víctimas de crímenes de Estado lograron posicionarse en la agenda pública, ésta vez a través de una nueva plataforma de visibilización y denuncia: el Costurero de la Memoria ${ }^{18}$.

En ese sentido, el reconocimiento de la responsabilidad de agentes estatales en la victimización en el marco del Acuerdo de Víctimas de La Habana, si bien fue una prerrogativa de la negociación, tampoco fue ajeno al acumulado y el posicionamiento de las víctimas a lo largo de estos procesos en particular, herederos de más cuatro décadas en general, de movilización y denuncia permanente.

La Fundación bebió de ese acumulado, proveniente del surgimiento de las primeras generaciones de defensores de derechos humanos en Colombia y América Latina, y lo potenció a través de nuevos repertorios para posicionar sus reivindicaciones y hacer pedagogía social, mismas que compartió con su propia generación a mitad de la década de 1990, y las generaciones venideras en la década del 2000 , las cuales igualmente apropiaron y potenciaron algunas de sus prácticas y discursos en la elaboración de su propia memoria y la lucha contra la impunidad.

La "Galería de la memoria" es, si se quiere, la experiencia más efectiva en esa dirección, por lo menos en dos sentidos: en tanto sentó puentes intergeneracionales al interior del movimiento de víctimas de crímenes de Estado, como por la "comunicabilidad" y la eficacia para transformar las percepciones de los ciudadanos que la visitan (D.G, 2016a) (González, 2016).

En conjunto con las prácticas renovadoras y las representaciones rupturistas respecto de lo que compromete la defensa de los derechos humanos, la Fundación también animó un debate de fondo, que produjo rupturas en el seno de la izquierda y la "familia humanitaria" colombiana: la solución política del conflicto armado como prerrogativa de la satisfacción de los derechos a la verdad, la justicia y la reparación de las víctimas de la criminalidad estatal. Esto se puede evidenciar en la producción académica de Claudia Girón e Iván Cepeda, y especialmente, en su actividad política tanto en el movimiento de víctimas como en el Senado de la República.

Quedan varios interrogantes para nuevas investigaciones sobre este tema: por lo pronto, un estudio comparado con otras experiencias de criminalidad estatal en América Latina, así como el análisis de sus repertorios de denuncia, abordado desde la perspectiva de la política cultural de las víctimas. Es importante también analizar

18 "Las madres de Soacha”, como se les reconoce en la opinión pública, son las madres de los jóvenes de este municipio que fueron asesinados por efectivos del ejército en inmediaciones del municipio de Ocaña, Santander. Las madres fueron fundadoras del Costurero junto con Claudia Girón y otras organizaciones defensoras de derechos humanos. 
a fondo esta categoría de acuerdo con la percepción de las personas que usualmente de identifican a través de ella. Por ejemplo, el asesinato de los jóvenes de Soacha no se dio por móviles políticos directos como sí se han realizado los de los militantes de la UP, aun así, unos y otros son identificados como víctimas de crímenes de Estado, aunque su reconocimiento en la sociedad ha sido igualmente diferencial, ¿Esto se debe a que se percibe a unos como inocentes mientras que a otros no, como afirma Claudia Girón? Otros estudios podrían ocuparse de la especificidad de las representaciones, las prácticas y los discursos de estas víctimas, así como la respuesta estatal a sus demandas. Tratar de explicar, por ejemplo, por qué los procesos judiciales para esclarecer su victimización no han dado mayores resultados en términos de investigación, condena y judicialización de los responsables.

\section{Referencias}

Acebedo, L. (2016). Las víctimas de crímenes de Estado en Colombia: de la invisibilidad a la construcción de una identidad dignificada. En, N. Pardo y J. Ruíz (Eds.) Víctimas, memoria y justicia: aproximaciones latinoamericanas al caso colombiano. Bogotá: Universidad Nacional de Colombia.

Acevedo, 0. (2012). Geografías de la memoria. Posiciones de las víctimas en Colombia en el período de justicia transicional (2005 - 2010). Bogotá: editorial Pontificia Universidad Javeriana.

Álvarez, S., Dagnino, E., y Escobar, A. (1999). Lo cultural y lo político en los movimientos sociales latinoamericanos. En A. Escobar (Ed.), El final del salvaje. Naturaleza, cultura y política en la antropología contemporánea. Bogotá: CEREC - ICAN. pp. 133-168.

Aranguren, J. (2012). La gestión del testimonio y la administración de las víctimas: el escenario transicional en Colombia durante la Ley de Justicia y Paz. Buenos Aires, Bogotá: Consejo Latinoamericano de Ciencias Sociales, Siglo del Hombre Editores.

Barrero, E. (2010). Memoria, silencio y acción social. Reflexiones críticas sobre por qué recordar en Colombia. Bogotá: Cátedra Libre Martín-Baró, Fundación Mundos Posibles y Fundación Manuel Cepeda Vargas.

Bitar, S. (2007). Los primeros pasos de los Derechos Humanos en Colombia: la adaptación estratégica del gobierno de Julio César Turbay. Bogotá: Facultad de Ciencias Sociales, Universidad de los Andes.

Briceño-Donn, M., Reátegui, F., Rivera, M. C., Uprimy, C. (Eds). (2009). Recordar en conflicto: iniciativas no oficiales de memoria en Colombia. Bogotá: Centro Internacional para la Justicia Transicional (ICTJ) Bouvier, V. (2014).

Cepeda, I. (2013). Justicia transicional para la democracia. En, A. Vargas (Ed), Diálogos de La Habana: miradas múltiples desde la universidad. Bogotá: Universidad Nacional de Colombia. 
Cepeda, I. y Girón, C. (1996). Amnesia social y guerra psicológica en los medios de comunicación. En, Fundación Manuel Cepeda Vargas (Ed.), La memoria frente a los crímenes de lesa humanidad. Bogotá: FMCV, Defensoría del Pueblo.

Cepeda, I. y Girón, C. (1998). Memoria y derechos humanos en América Latina. En, Fundación Manuel Cepeda Vargas (Ed), Duelo, memoria y reparación. Bogotá: FMCV, Defensoría del Pueblo, Ministerio de Cultura.

Cepeda, I. y Girón, C. (1999). Procesos de inculturación. Problemas y conceptos de la apropiación de algunas corrientes del pensamiento social contemporáneo en Colombia. Bogotá: Colciencias, Pontificia Universidad Javeriana.

Cepeda, I. y Girón, C. (2004a). Olvido o memoria en las condiciones de solución de conflictos políticos. Revista Aquelarre (5), pp. 23, 34.

Cepeda, I. y Girón, C. (2004b). Justicia y crímenes contra la humanidad. Análisis político (50). pp. 52, 71.

Cepeda, I. y Girón, C. (2005a). Justicia, memoria y exilio. En, M. Wolf (Comp.) Regresan siempre en primavera. Colombia: luz y sombra de un proceso hacia la paz. Barcelona: Icaria Editorial - Antrazyt, pp. 157 - 185.

Cepeda, I. \& Girón, C. (2005b). La segregación de las víctimas de la violencia política. En, A. Rettberg (Comp.), Entre el perdón y el paredón: preguntas y dilemas de la justicia transicional. Bogotá: Universidad de los Andes, Centro de Estudios Socioculturales e Internacionales, Centro Internacional de Investigaciones para el Desarrollo, pp. 259, 281.

Dudley, S. (2008). Armas y Urnas. Bogotá: Editorial Planeta.

Escobar, A., Álvarez, S., y Dagnino, E. (2001). Política cultural y cultura política. Una nueva mirada sobre los movimientos sociales latinoamericanos. Bogotá: ICANH, Taurus.

Girón, C. y Silva, L. (2010). La reconciliación y el perdón en el marco de la reparación integral. Revista Javeriana, (768), pp. 45, 55.

Girón, C. \& Vidales, R. (2010). El rol reparador y transformados de la memoria: de la eficacia simbólica a la acción política colectiva. En, E. Barrero (Ed.), Memoria, silencio y acción social. Reflexiones críticas sobre por qué recordar en Colombia. Bogotá: Cátedra Libre Martín-Baró, Fundación Mundos Posibles y Fundación Manuel Cepeda Vargas.

Girón, C. \& Bustamante, F. (2013). La galería de la memoria “Somos Tierra”. Una propuesta pedagógica y estética de reparación simbólica a partir de la resignificación de las memorias, construida con las víctimas y desde los territorios afectados por la violencia. Revista Javeriana (796), pp. 50, 56.

Gómez, G. (2014). Justicia transicional en disputa. Una perspectiva constructivista sobre las luchas por la verdad, la justicia y la reparación en Colombia, 2002 - 2012. Medellín: Editorial Universidad de Antioquia. 
González, D. (2016). Emociones y cultura política. Análisis de las galerías de la memoria presentadas por el Capítulo Bogotá del Movimiento Nacional de Víctimas de Crímenes de Estado (Movice). Estudios políticos (48), pp. 157-178.

Grupo de Memoria Histórica. (2009). Memorias en tiempos de guerra: repertorio de iniciativas. Bogotá: punto aparte editores.

Mosquera, C. (2015). La progresiva emergencia de las víctimas como agentes políticos en Colombia. En, A. Vargas (Ed.), Transición, democracia y paz. Bogotá: Centro de Pensamiento y Seguimiento al Diálogo de Paz, Universidad Nacional de Colombia.

Ochoa, A. M. (2003). Entre los deseos y los derechos. Bogotá: Instituto Colombiano de Antropología, ICAN.

Quiroga, J. \& Gómez, R. (1996). La denuncia contra el Estado colombiano por el genocidio de la Unión Patriótica como contribución a la recuperación de la memoria de crímenes de lesa humanidad en Colombia. En, Fundación Manuel Cepeda Vargas (Ed.), La memoria frente a los crímenes de lesa humanidad. Bogotá: FMCV, Defensoría del Pueblo.

Rettberg, A. (2012). Un marco analítico para la construcción de paz en Colombia. En A. Rettberg (Ed.), Construcción de paz en Colombia. Bogotá: Universidad de los Andes.

Rettberg, A. (2015a). Victims of the Colombian Armed Conflict: The Birth of a Political Actor. In B. Bagley \& J. Rosen (Eds.), Colombia's Political Economy at the Outset of the 21st Century: From Uribe to Santos and Beyond, Lexington Books, pp. 111 - 139.

Rettberg, A. (2015b). Ley de víctimas en Colombia: un balance. Revista de Estudios Sociales (54), pp. 185 - 188.

Sarlo, B. (2005). Tiempo pasado. Buenos Aires: siglo veintiuno editores.

Uprimny, R. \& Saffon, M. (2009). Usos y abusos de la justicia transicional en Colombia. En, A. Rangel (Ed.). Justicia y paz ¿Cuál es el precio que debemos pagar? Bogotá: Editorial Intermedio.

\section{Entrevistas}

Claudia Girón Ortíz, agosto 18 de agosto de 2016 (C.G, 2016a)

Claudia Girón Ortíz, septiembre 1 de 2016 (C.G, 2016b)

Juan Pablo Aranguren, septiembre 16 de 2016 (J.P.A, 2016)

Diana Gómez, octubre 25 de 2016 (D.G, 2016)

José Antequera, noviembre 10 de 2016 (J.A, 2016) 


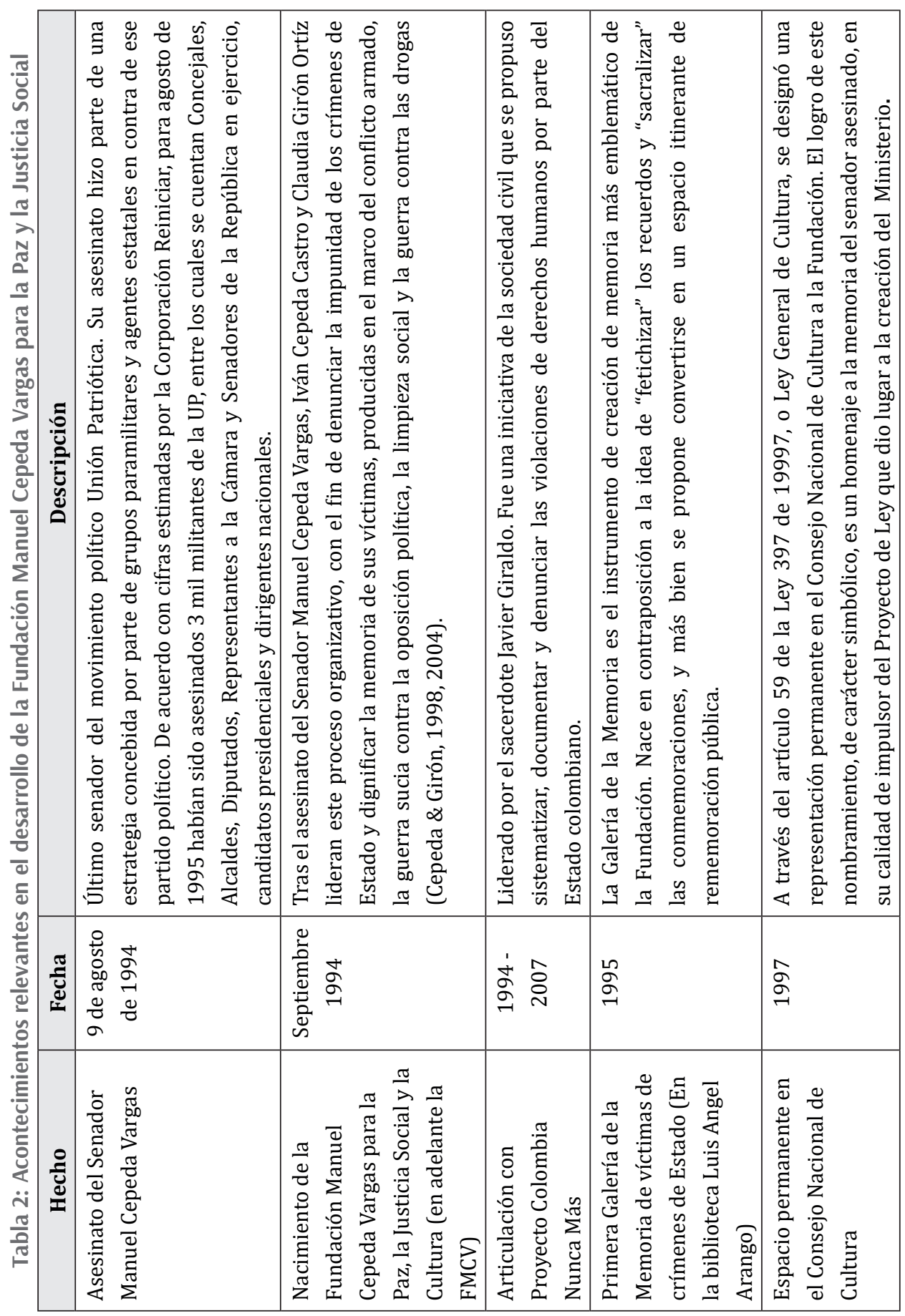




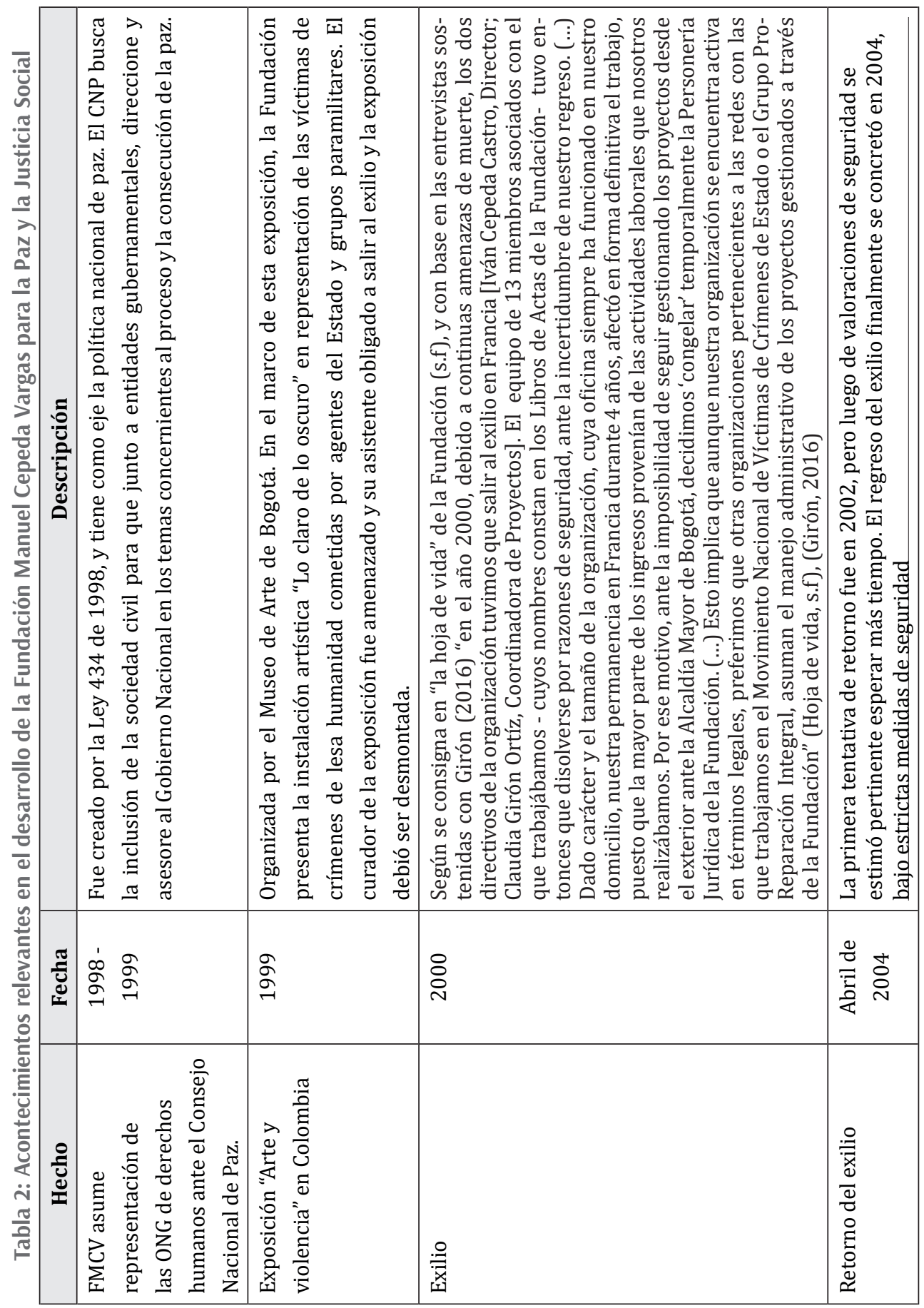




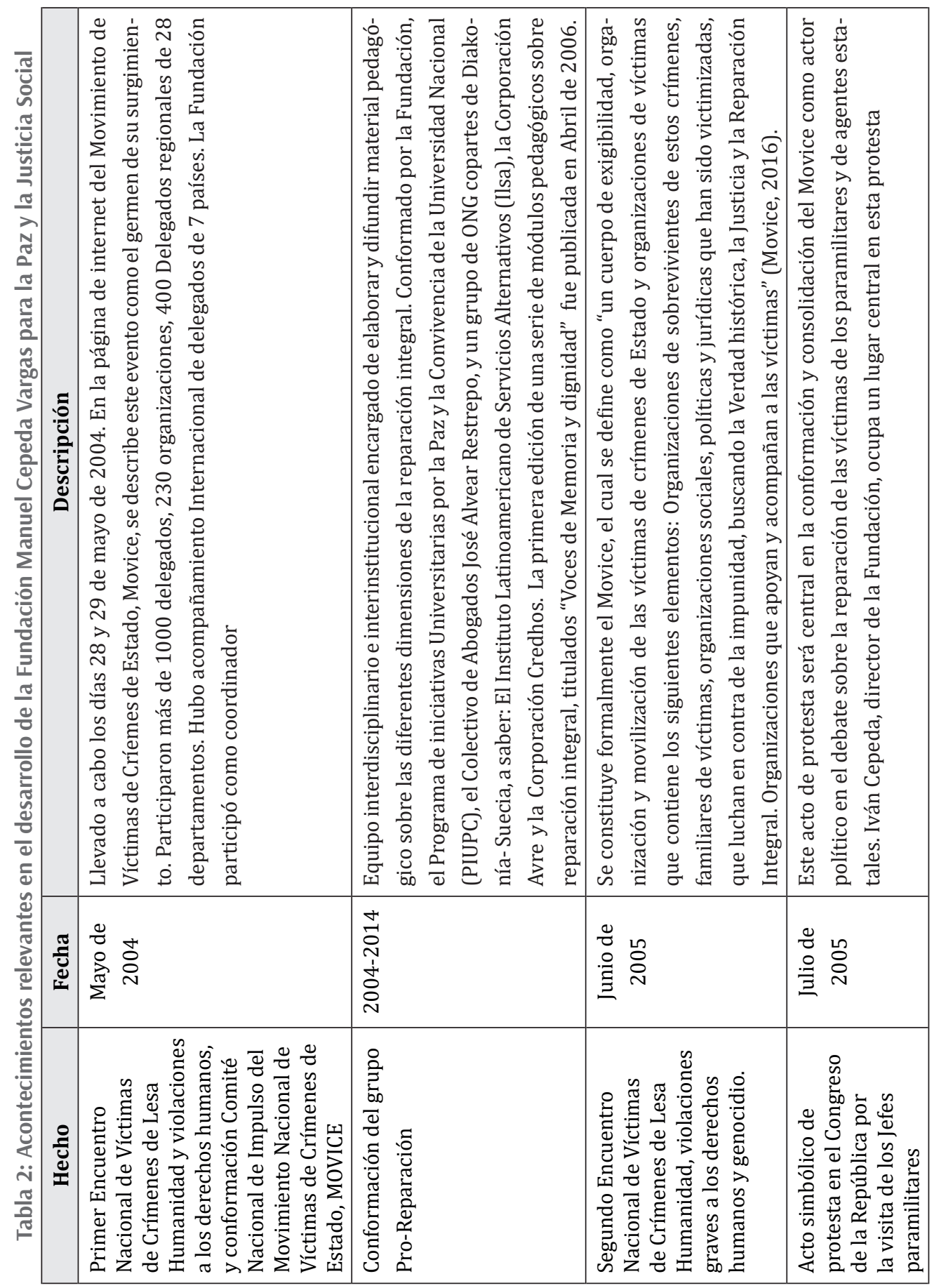




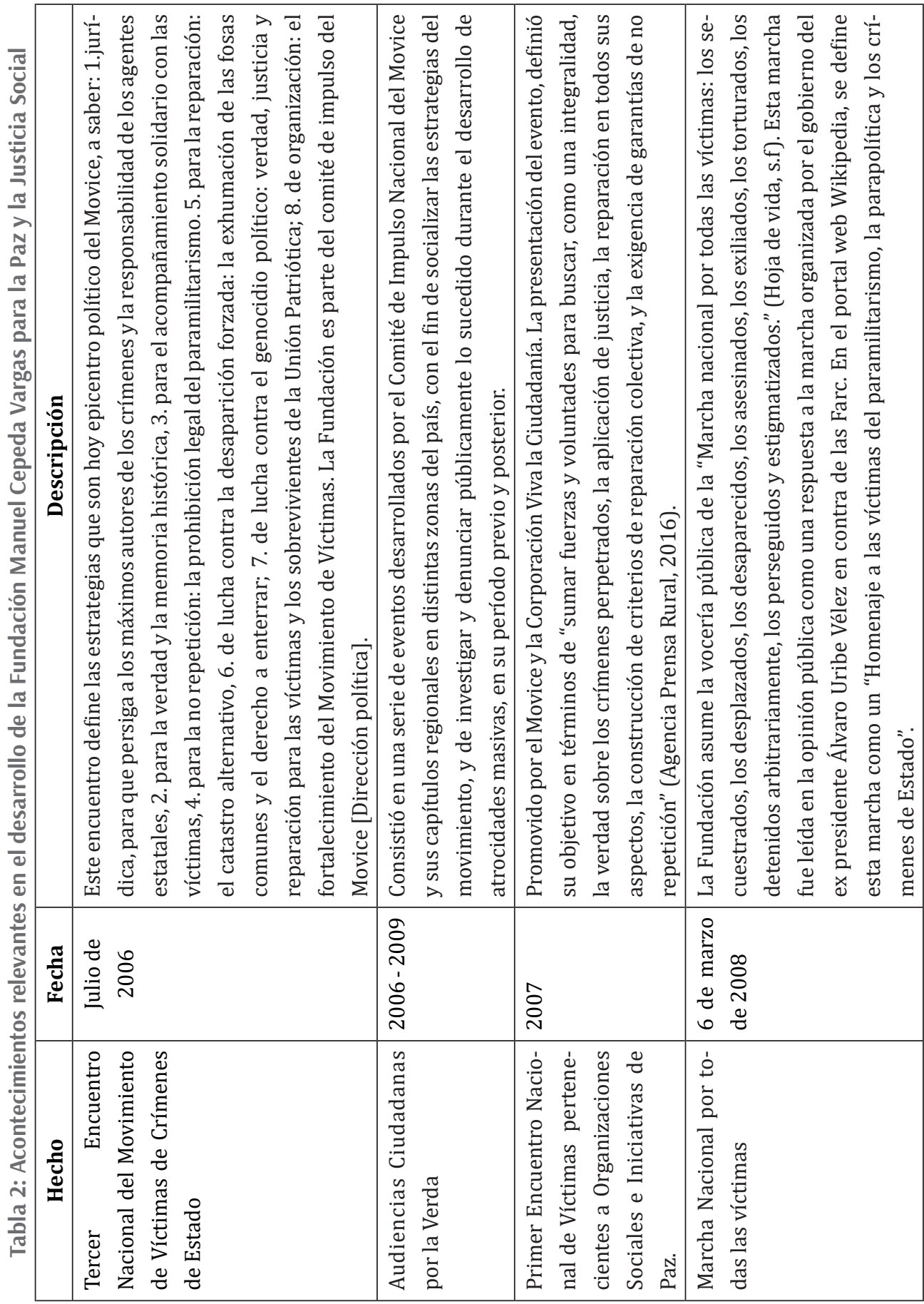




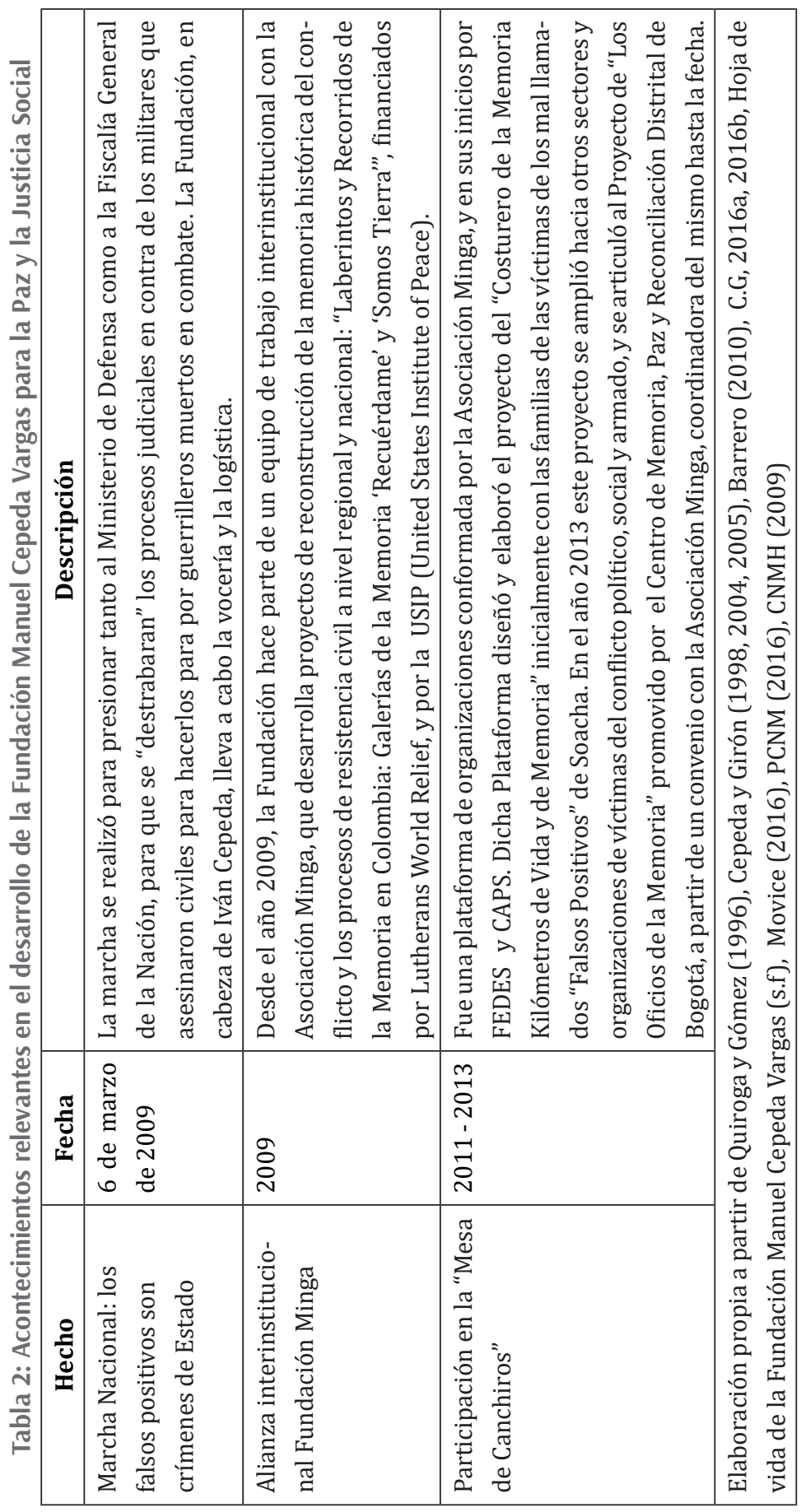


